
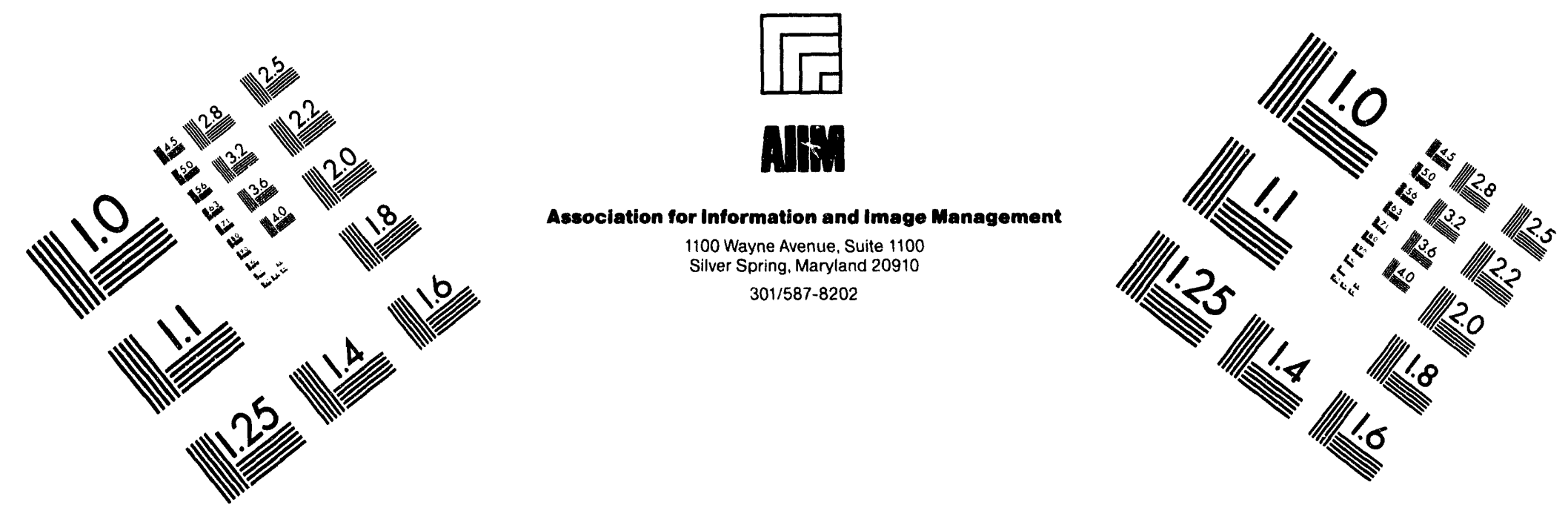

\title{
Centimeter
}

$\begin{array}{llllllllllllllll}1 & 2 & 3 & 4 & 5 & 6 & 7 & 8 & 9 & 10 & 11 & 12 & 13 & 14 & 15 & \mathrm{~mm}\end{array}$

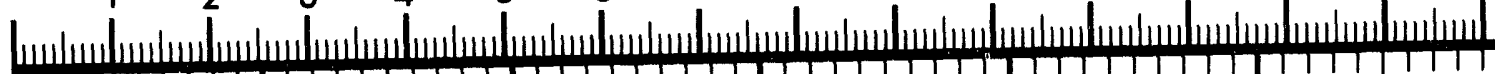

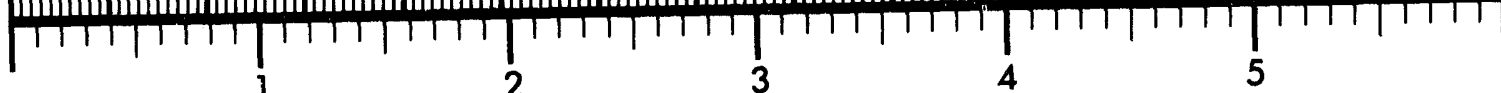
Inches
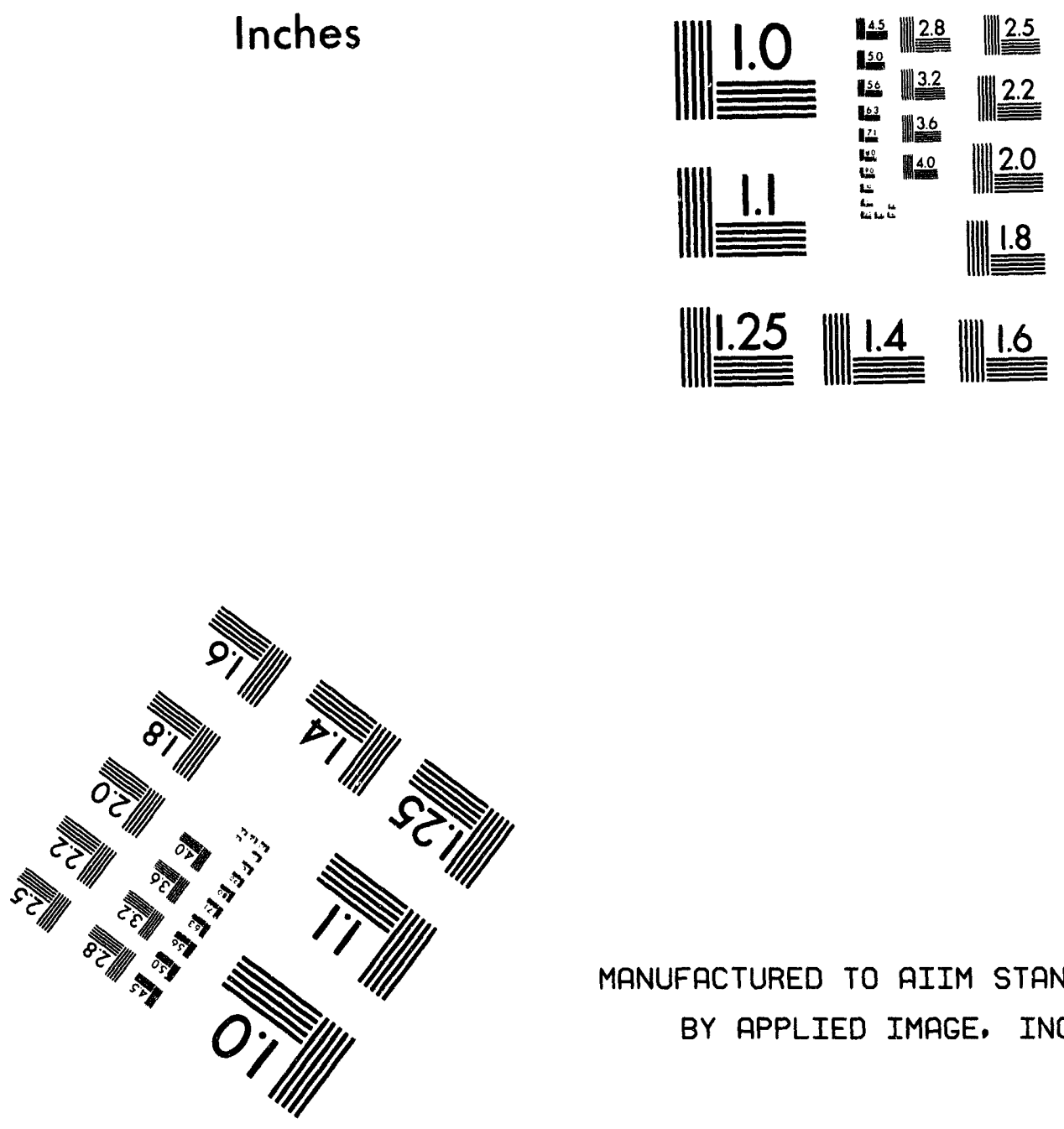

MANUFACTURED TO AIIM STANDARDS BY APPLIED IMAGE, INC.

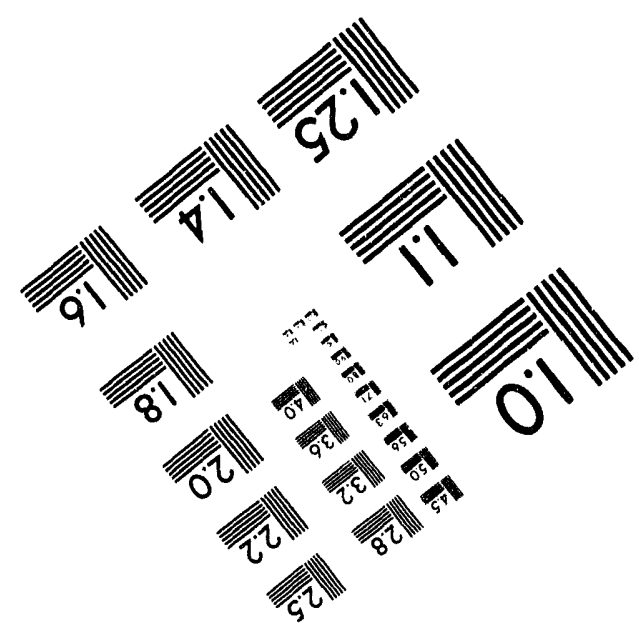



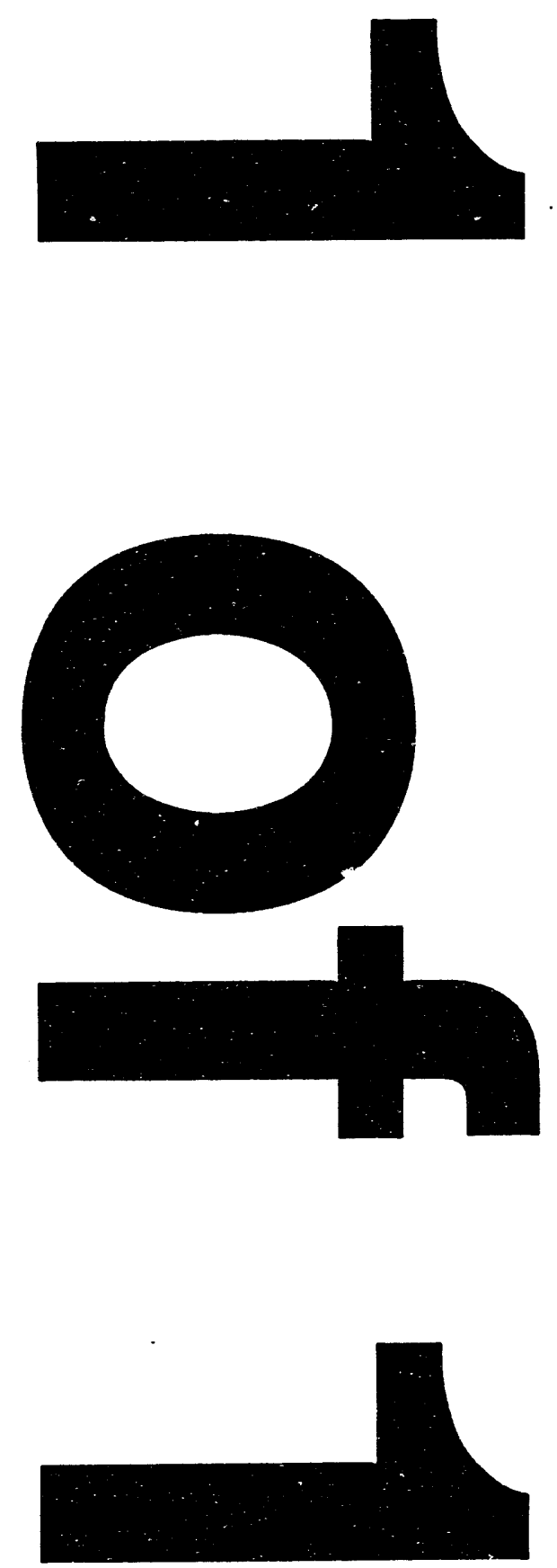


\section{Hw- 65579}

\section{Cover Sheet for a Hanford Historical Document Released for Public Availability}

Released 1994

Prepared for the U.S. Department of Energy under Contract DE-AC06-76RLO 1830

Pacific Northwest Laboratory

Operated for the U.S. Department of Energy

by Battelle Memorial Institute 


\section{DISCLAIMER}

This is a historical document that is being released for public availability. This was made from the best available copy. Neither the United States Government nor any agency thereof, nor Battelle Memorial Institute, nor any of their employees, makes any warranty, express or implied, or assumes any legal liability or responsibility for the accuracy, completeness, or usefulness of any information, apparatus, product, or process disclosed, or represents that its use would not infringe privately owned rights. The views and opinions of authors expressed herein do not necessarily state or reflect those of the United States Government or any agency thereof. 


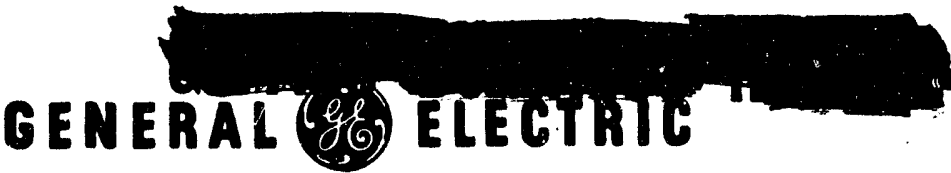

MANFORD ATOMIC PRODUCTB OPERATION - FICHLAND, WASHINGTON

DOCUMENT NO.

HW -65579

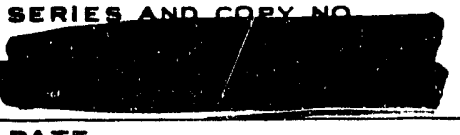

DATE

June 14, 1960

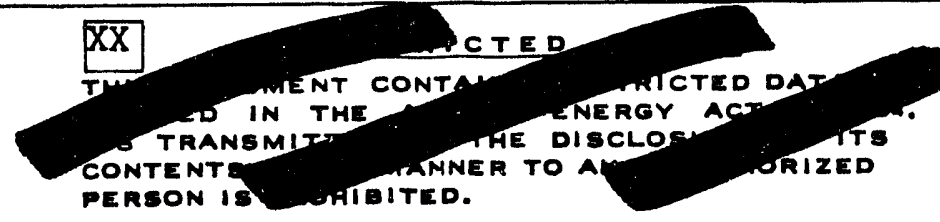

OTHER OFFICIAL CLABEIFIED INFORMATION

THIS MATERIAL CONTAINB INFORMATION AFFECTING

THE NATIONAL DEFENSE OF THE UNITED STATEB WITHIN THE MEANING OF THE ESPIONAGE LAWE, TITLE 18, U.8.C., SEC8. T3 AND TOA, THE TRANBMISEION OR REVELATION OF WHICH IN ANY MANNER TO AN UNAUTHORIZED PERSON IS PROHIEITED DY LAW.

TITLE

MEASUREMENT OF FUEL ELEMENT BOND

\section{STRENGTH}

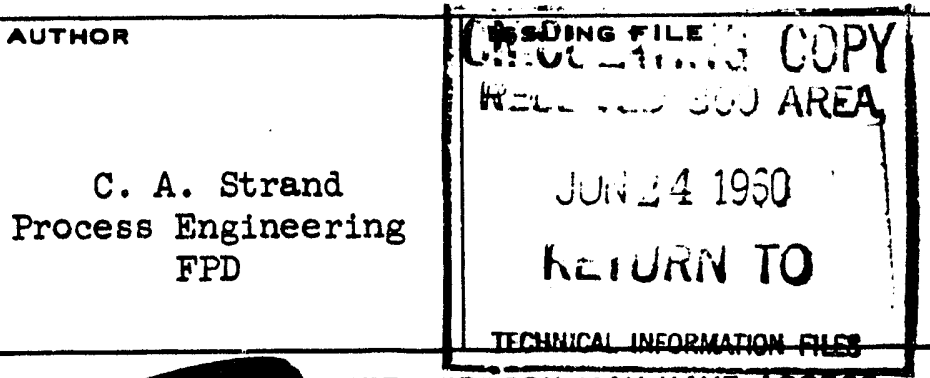

THIS DOCUN MUET NOT DE LEFT UM SENDED OR WHERF PRIZED PERSON MAYHAVE XCCLBE

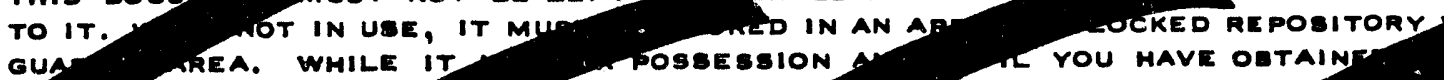

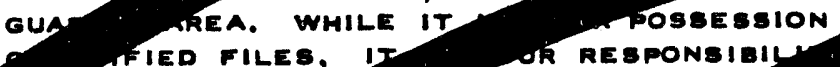
S PROJECT AND, IT STY UNAUTHORIZ OF REBIDENCE OBTAIN THF TO BIGN: IT REBPONBIEIL TEEP IT AND ITS CO
ON. ITE TRANBMITTAL
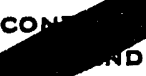
NITHIN THE LIN
STORAOE AT ATIONAL COPIEB THIS DOCUMEINT OHIBITED. IT IS O OE DUPLICATED
THE RELATEO BPACE PROVIDED E, NT.

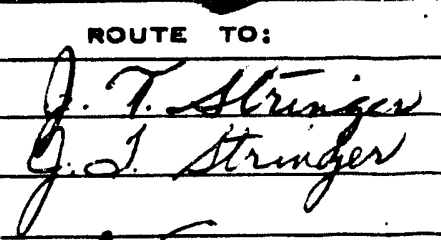

\begin{tabular}{c|c} 
PAYROLL NO. & LOCATION \\
927 & 3703 \\
927 & 3703 \\
& \\
\hline 269 & 3
\end{tabular}

\begin{tabular}{l} 
FILES ROUTE \\
111 \\
\hline
\end{tabular}

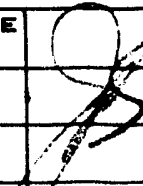
gignature AND DATE

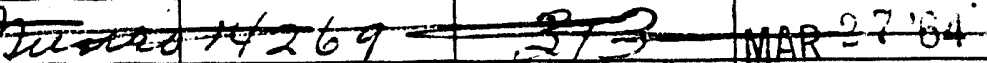
A $20-624$

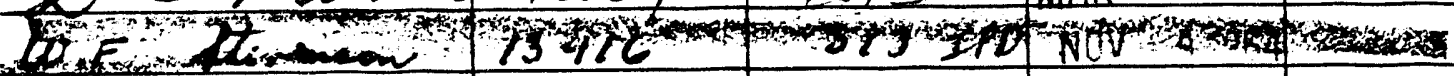

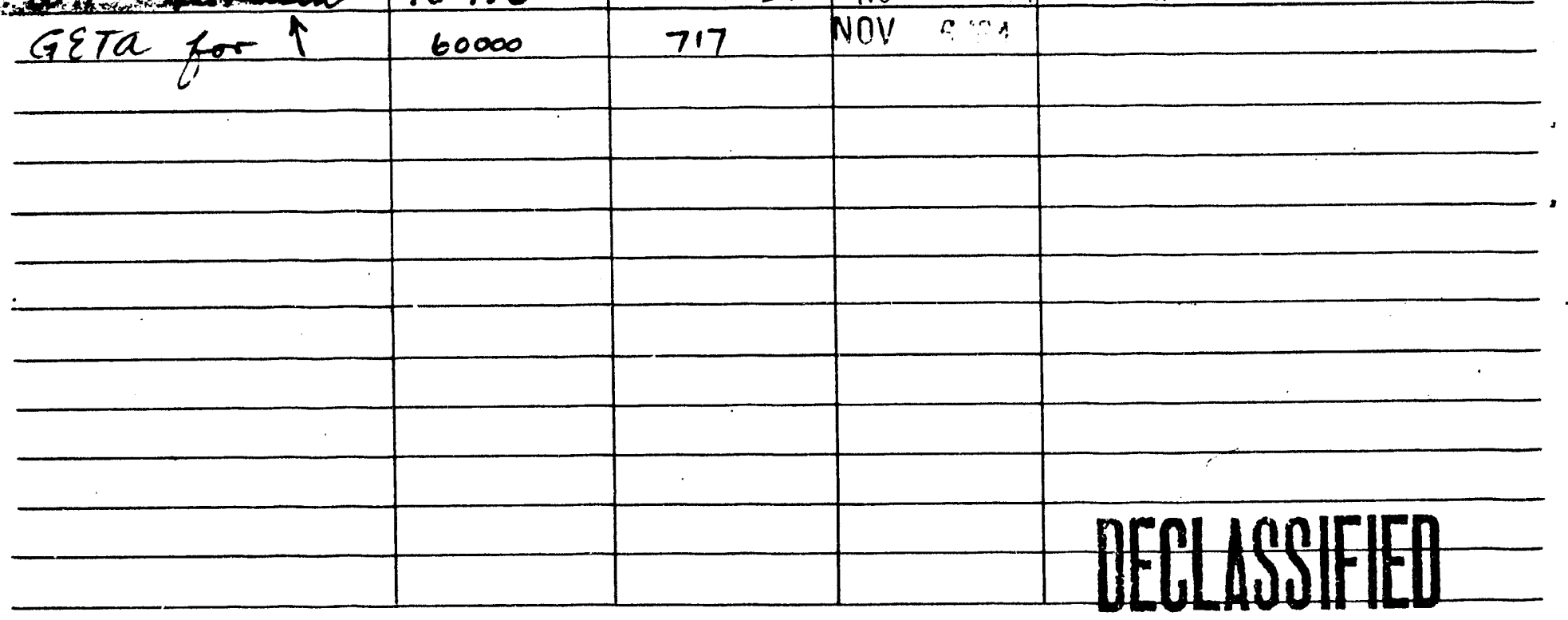




\section{DECLLSSFFIED}

HW-65579

This document consists of 11 pages,

June 14, 1960

MEASUREMENT OF FUEL ELEMENT BOND STRENGTH

C. A. Strand

Engineer, Process Engineering

Fuels Preparation Department

DISTRIBUTION

1. WA Blanton
2. AG Blasewitz
3. CA Burgess
4. FW Grubb
5. IT Hagie
6. GB Hansen
7. JI Jaech
8. HP Kraemer
9. WM Mathis
10. HC Money
11. TD Naylor
12. CA Strand
13. JT Stringer
14. JW Talbott
15. JC Tverberg
16. EA Weakley
17. Record Center
18. 300 Files
21. Extra

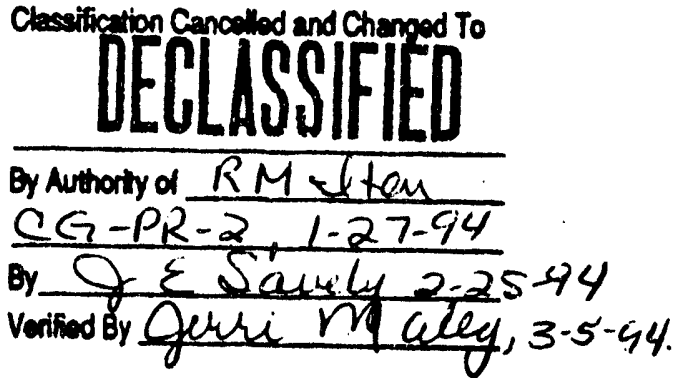

19-21. Extro

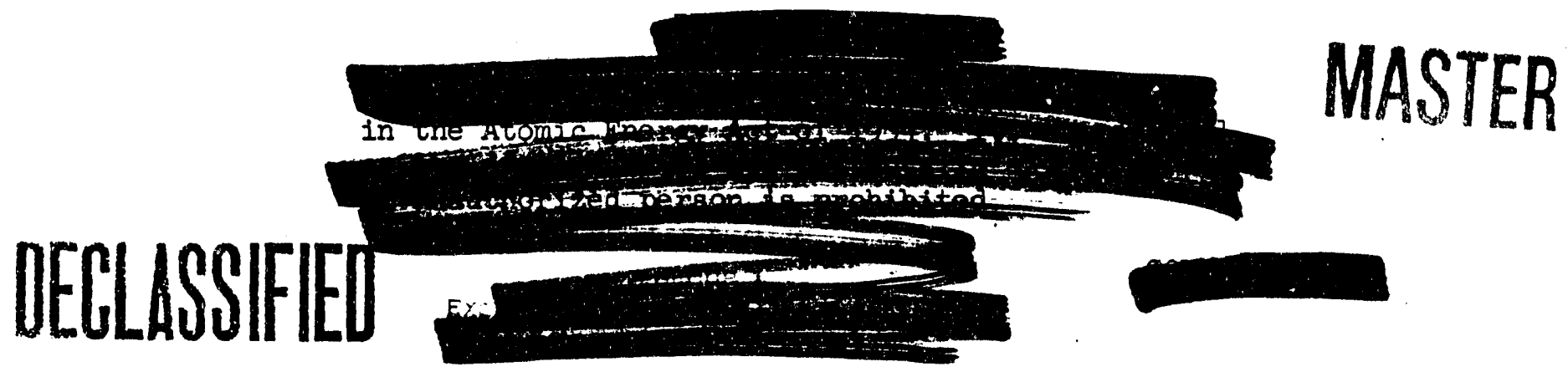




\title{
DEELLSSFFIED
}

HW- 65579

\author{
MEASUREMENT OF FUEL ELEMENT BOND STRENGTH
}

\section{Introduction}

Until recently, bond adherence between the Al-SI braze layer and the uranium core was estimated by a method known as the "chisel test". Fuel element jackets were removed from the core using a hammer and chisel, and the relative bond strength was estimated on a comparison basis. Bonds were classified as normal, below normal, or better than normal, depending upon the ease with which the jacket was removed. The weakest bonds were usually found one-to-two inches below the fuel element cap, but on occasions extended as far as five inches below the cap prior to making process changes in the duplex canning bath to improve bonding.

Af ier duplex furnace conditions were changed (silicon concentration, core submersion depth, and temperature) during September, 1958, the weak bond. area was reduced to $a$ band $1 / 4$ inch to 1 inch below the cap end of the piece.

Recently, the stud-pull method for determining bond strength was developed providing a better method for measuring bond quality. Bond strength measured by the stud-pull method provides actual tensile strength measurements, which are valuable for test purposes and detecting in-process variations. This report summarizes tests made using the Instron Tensile Strength Machine for determining fuel element bond strength.

Suminary

The stud-pull method for determining fuel element bond strength has been developed sufficlently to serve as an additional measurement of bond quality. The test is capable of detecting variation in bond strength produced by changing process variables which affect bonding. Average production fuel element bond strength has been determined to be over 13,500 psi tensile strength with actual values varying from 4000 psi to 20,000 psi.

Bond strength measurements are made by welding $1 / 4$ in. diameter studs to the fuel element jacket by the Graham Stud Welding Process. The Instron Tensile Strength Machine is then used to pull the stud and measure the force required to break the bond.

Although only limited data is avallable on fuel elements preheated with horizontal agitation, the stud-pull method for determining bond strength has been demonstrated to be capable of detecting variations in bond

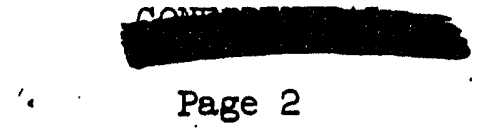


strength of fuel elements preheated in the sixty-degree duplex basket. Measurement of bond strength of cores preheated in the horizontal basket is continuing.

It is recommended that quality Control use this test in the Quality Certification program as an added means for measuring, controlling, and/or. predicting fuel element quality.

Discussion

Comparative fuel element bond strengths were previously determined using the "chisel test". As implied, this test was performed by removing the fuel element cap and base ends and stripping the jacket from the core with a hammer and chisel. Bcnd strengths were estimated by comparing the difference in manual force required to remove the jacket, the scund of the breaking bond, and the appearance of both the core and can surfaces after jacket removal. Generaliy, bond strengths fell into three categories of normal, below normal, and better than normal.

Although the "chisel test" was subjective in nature, it served as a valueible tool. During earlier tests for improving luel element bonding, the "chisel test" was the only convenient method available for estimating the effect of process changes on bond strength. Initial applications of the stud-pulling technique(1) offered a direct method for measuring bond tensile strength. Through use of this test, it will be feasible to design better tests for improving bond quality and measure the resulting changes in bond strength.

Bond strength is measured by welding an $1100-\mathrm{H} 18$ alloy aluminum stud to the fuel element jacket, and pulling the stud witn an Instron Tensile Strength Machine. The aluminum stud is made according to a patent held by the Graham Stud Welding Company. (See Drawing No. H-3-7993.) Studs are welded to the fuel element jacket using a Graham Stud Welder set as follows: amperage - 215; pressure - $75 \mathrm{psig.} \mathrm{The} \mathrm{fuel} \mathrm{element} \mathrm{with} \mathrm{attached} \mathrm{studs}$ is placed in the carriage of the Instron Tensile Strength Machine and secured in line with the jaws on the crosshead. A large number of crosshead speeds and chart speeds are avallable on the present test equipment. A combination of crosshead speed of 0.02 inch per minute, a shart speed of 0.5 inch per minute, and a chart range of 0 to 2000 pounds has been found to be satisfactory for measuring fuel element bond tensile strength.

Recently a controlled test was made to determine whether the "stud-pull method" could detect the variation in bond strength normally observed by the "chisel test". Fuel elements were fabricated using three different

1. Tverberg, J. C., "Bond Strength Evaluation of the Brittle Bond Problem in Production Fuel Elements". November 10, 1958. (ConfidentialUndocumented) 
levels of duplex furnace Al-Si silicon content (8.5\%, 9.5\%, and $10.5 \%$ ) to produce varying amounts of weak (brittle) bonds. As in the past, the higher the silicon concentration, the larger the area of weak bonding. This was verified by pulling four studs on each of thirty (jo) fuel elements. Bond strengths as measured by the stud-pull test are shown in Fig. 1. Note that as the silicon content decreases, the area of strong bonding increases as if by pushing the weaker bond up and off the top end of the piece. Statistical analysis $(2)$ of the test data indicates that there is a very strong difference between bond strength measured at the top end of the rieces and that measured at the center and base, which is essentially the same. Due to the small sample size at varying duplex furnace temperatures, there was no significant temperature effect upon bond strength detected. However, the effect of duplex Al-Si silicon content was significant. Results of the statistical analysis of these data are shown in Fig. 2; where bond strengths are plotted against duplex furnace Al-S1 silicon content. The bond strength data are summarized by showing a comparison of average strength, minimum strength, and maximum minus minimum strength. Note in these curves that average bond strength maximizes at a silicon content of about 9.5\%. There are two reasons for this increased strength at $9.5 \%$ silicon using the sixty-degree preheat basket. At higher silicon concentrations, increased amounts of the brittle laminar compound layer are formed at the top of the core. At lower concentrations, a considerably thicker UAl 3 -type compound is formed at the base end of the core, which is slightly weaker than that formed at $9.5 \%$ silicon content. Average minimum strength decreases as the silicon content increases because of the pronounced "brittle bonding" produced with the sixty-degree preheat basket at higher silicon levels. A third line has been added to show the relationship between the maximum and minimum bond strengths. This line is straight and shows a difference of 375 pounds force at $10.5 \%$ silicon, decreasing to 230 pounds force at $8.5 \%$ silicon. The general reduction in difference is due to less "brittle bonding" at the top end of core as the Al-Si silicon content is reduced. A slight decrease in middle and base end bond strength at the low silicon level also contributed to the reduction in the difference between maximum and minimum values.

Bond strengths of two-hundred (200) I \& $E$ fuel elements produce in the 313 Building were determined and the raw data was statistically (3) analyzed. These data show that there was no difference between bond strengths taken one inch from each end and in the center of the fuel element. No differences were observed because the area of weak "brittle bonding" when using the sixty-degree basket is just above the spot where the upper stud is welded. (This typical cap-end brittle area has since been eliminated by use of the horizontal duplex basket.)

2. Jaech, J. I. Personal Communication. May 5, 1960. 3. op. cit., J. L. Jaech, reference 2. 
Average Jond strength by canning line and lot for the production fuel elements was determined by pulling studs from six pleces per line per 1ot. The average of these pieces was found to be 15,040 psi tensile strength, corresponding to 737 pounds force, the direct chart reading which is a more convenient method for expressing bond strength. Data from these tests are shown in Fig. 3 and 4 . FIg. 3 is a control chart with three sigma limits showing the average bond strength by line. Fig. 4 shows the average bond strength and range per lot.

It is recommended that the control chart method for showing bond strength be adopted by Quality Control for the Quality Certification Program. Since large changes in bond strength are of major concern, it is suggested that average bond strength and range be recorded for each canning line and production lot, to express the bond strength of outgoing fuel elements. By pulling three studs from each of five pieces per line shift, it will be possible to detect both line variation and lot/or shift variation in bond strength. There is a probability of 93\% for detecting a line variation of 200 pounds force in five samples. Since the lot/or shift sample will be larger, the possibility of detecting smaller changes will increase as shown in Fig. 5. Probability for detecting changes in average bond strength ranging from 25 to 300 pounds force for a given sample size is given in Fig. 5. (4) Expressing the lot average and range will also be a valuable development tool for use in measuring future improvements in fuel element bonding. It appears that it would be desirable to maintain the present average bond strength, but to produce greater uniformity within each piece and lot.

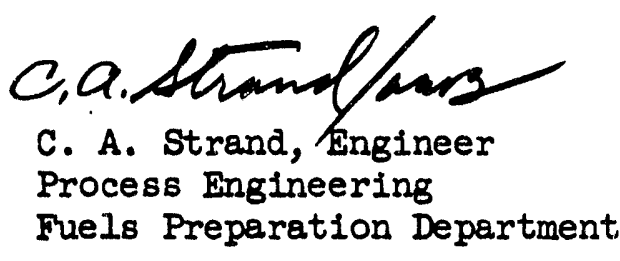

CAS:gab

4. op. cit., J. I. Jaech, Page 4.

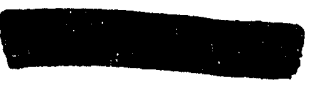

Page 5

CHANGE DATED......................... 


\section{REFERENCES}

1. Tverberg, J. C., "Bond Strength Evalua iun of the Brittle Bond Problem in Production Fuel Elements". November 10, 1958. (Confidential-Undocumented)

2. Jaech, J. I. Personal Communication. May 5, 1960.

3. Jaech, J. L. Personal Communication. May 5, 1960.

4. Jaech, J. L. Personal Communication. May 5, 1960. 
HW-65579

\section{DECLLSSFFIED}

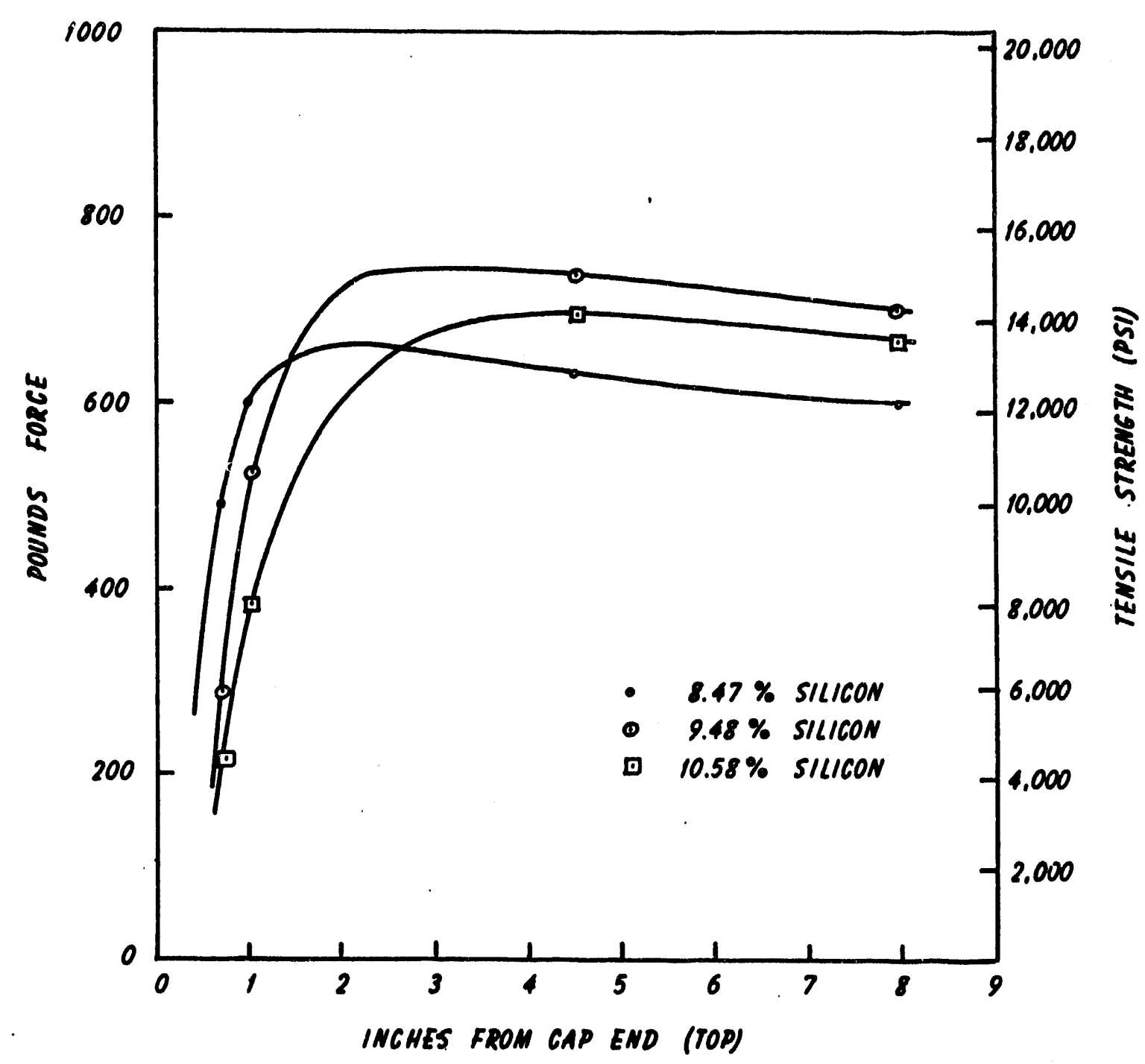

Fig. 1

AVERAGE FUEL ELEMENT BOND STRENGTH ACCORDING TO IOCATION MEASURED ON CCRES PREHEATED IN THE SIXTY DEGREE DUPLEX BASKET AND BRAZED WITH VARYING SIIICON CONTENT AI-SI 


\section{OECLLSSFIFED}

HW- 65579

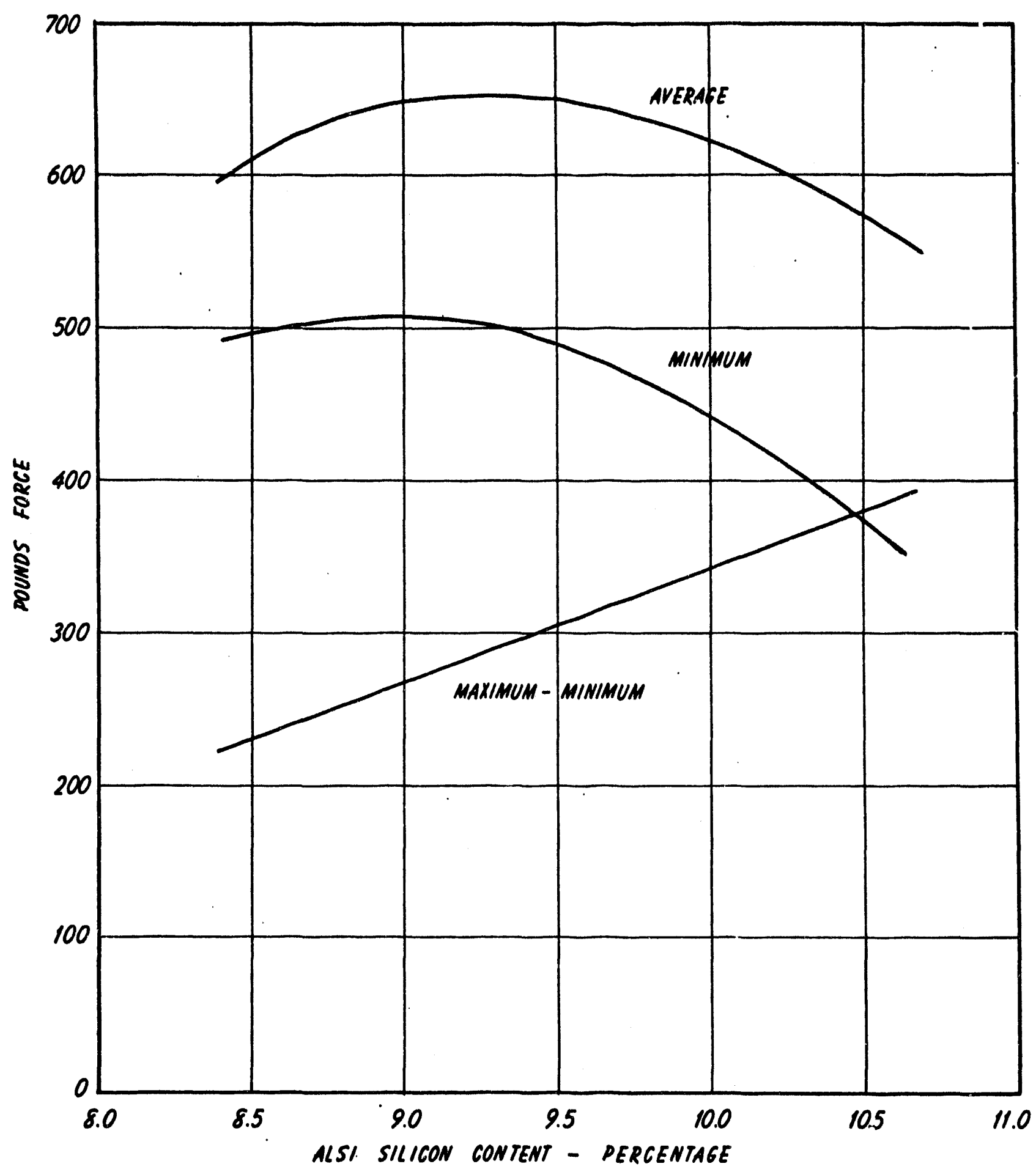

Fig. 2

EFFECT OF DUPIEX FURNACE AI-SI SIIICON CONMENT UPON FUEL ELEMENT BCND STRENGTH 


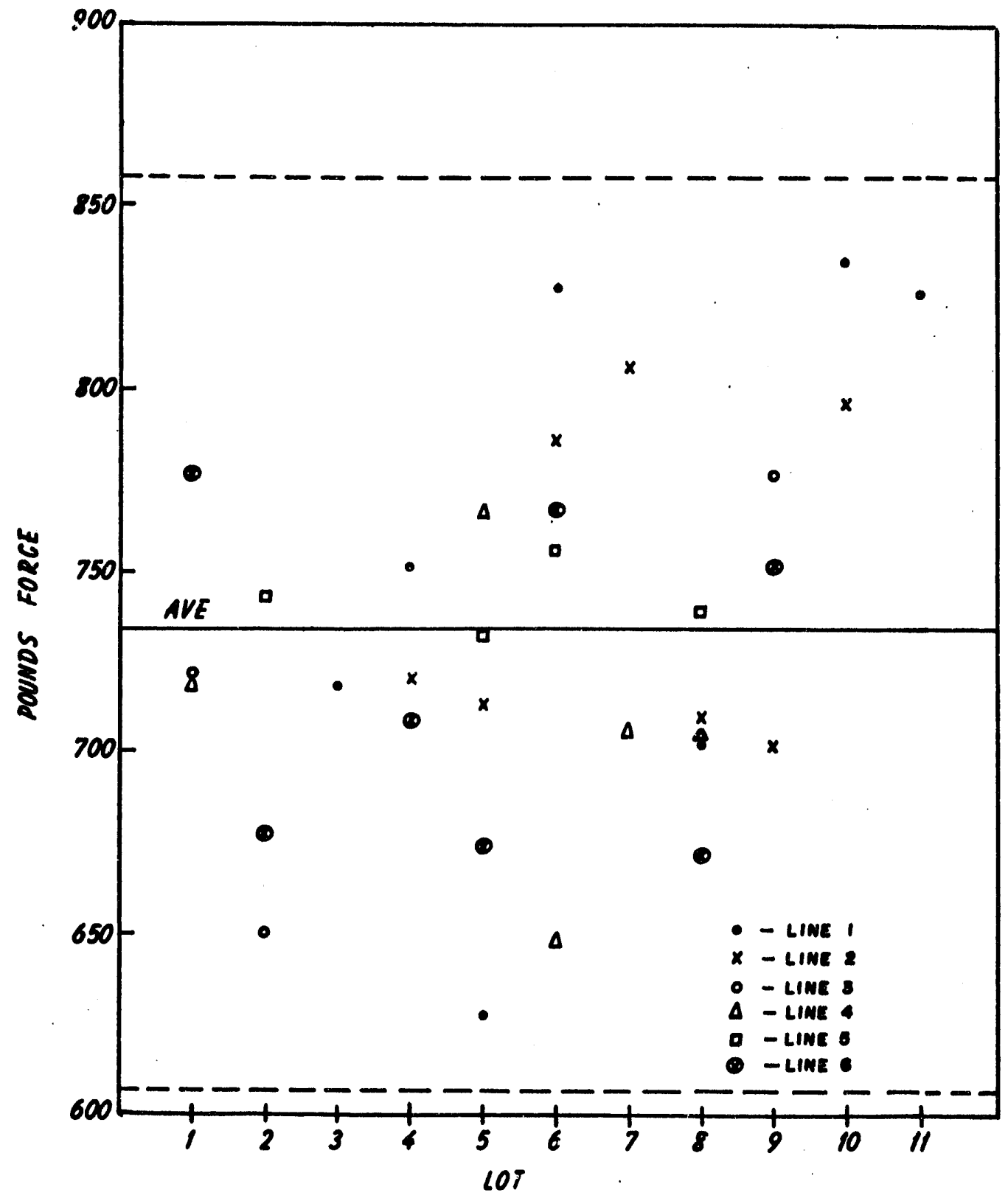

F士g. 3

Control chart showing average bond strength by line. Each point is the average bond strength for six fuel elements. Three sigma limits are shown.

Page 9 


\section{DECLASSIFIED}

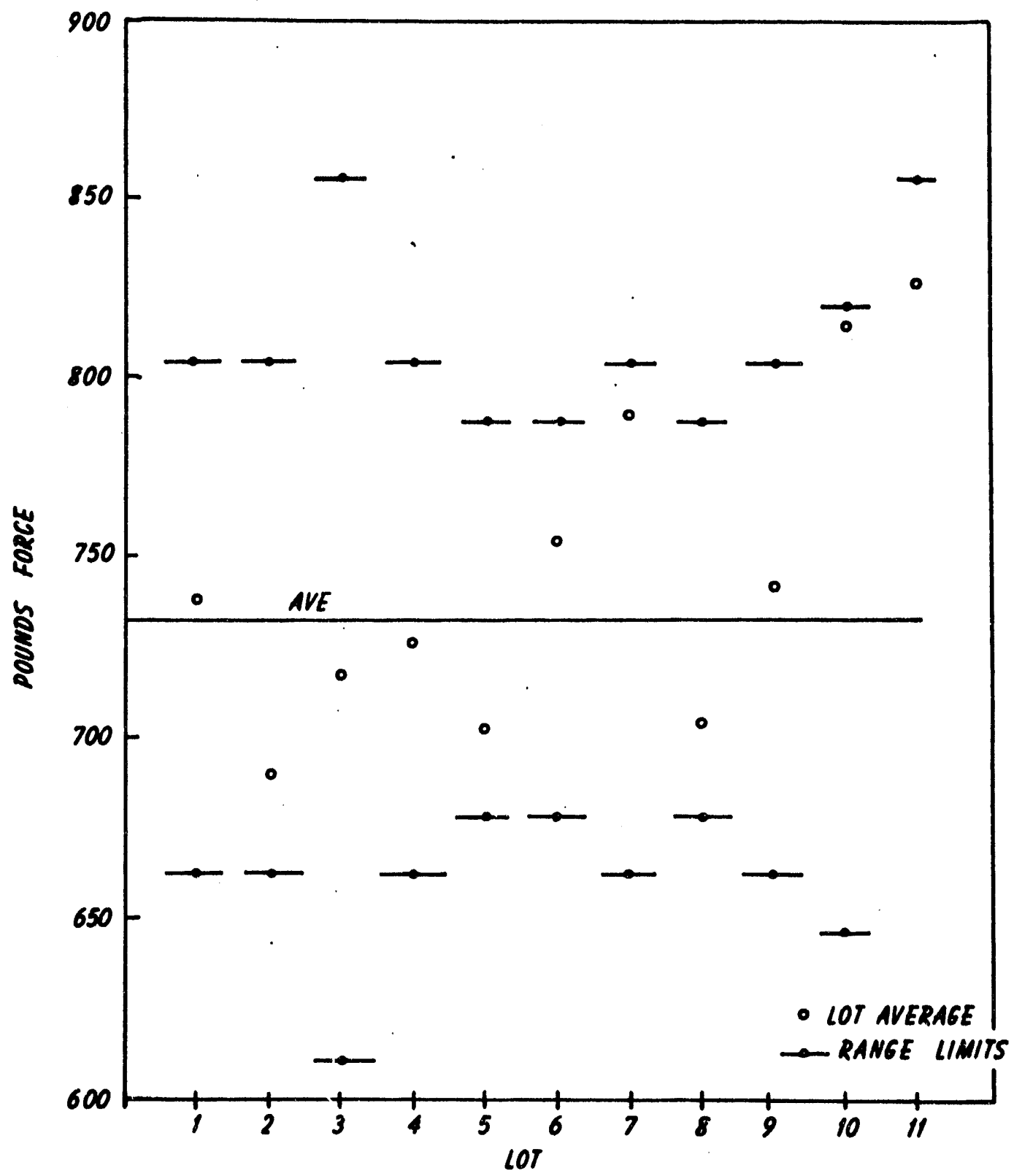

Fig. 4

Control chart showing average bond strength and range per fuel element lot. 


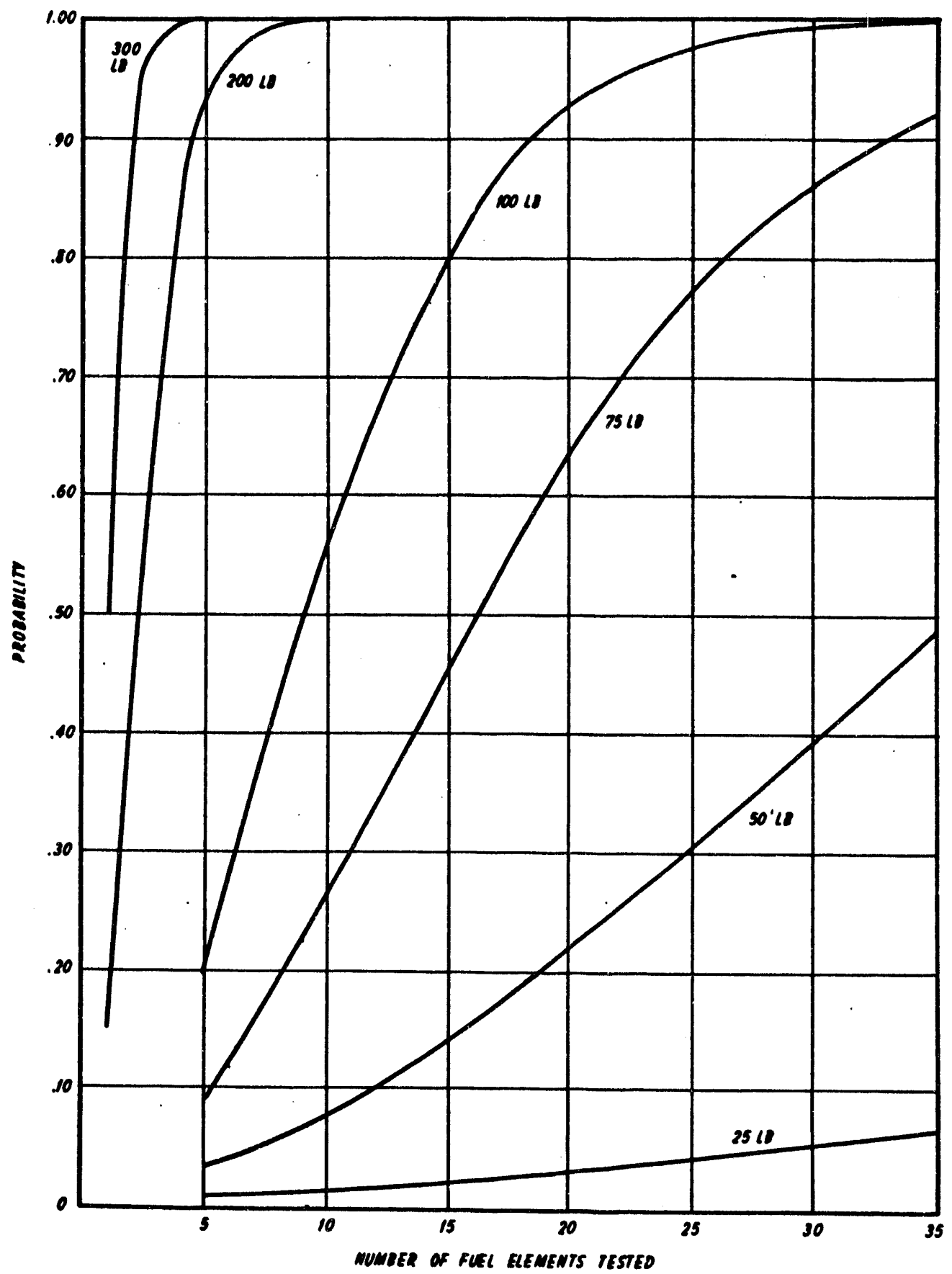

FIGURE 5 - PROBABILITY FOR DETECTING CHANGES IN AVERAGE BOND STRENGTH FOR A GIVEN SAMPLE SIZE 

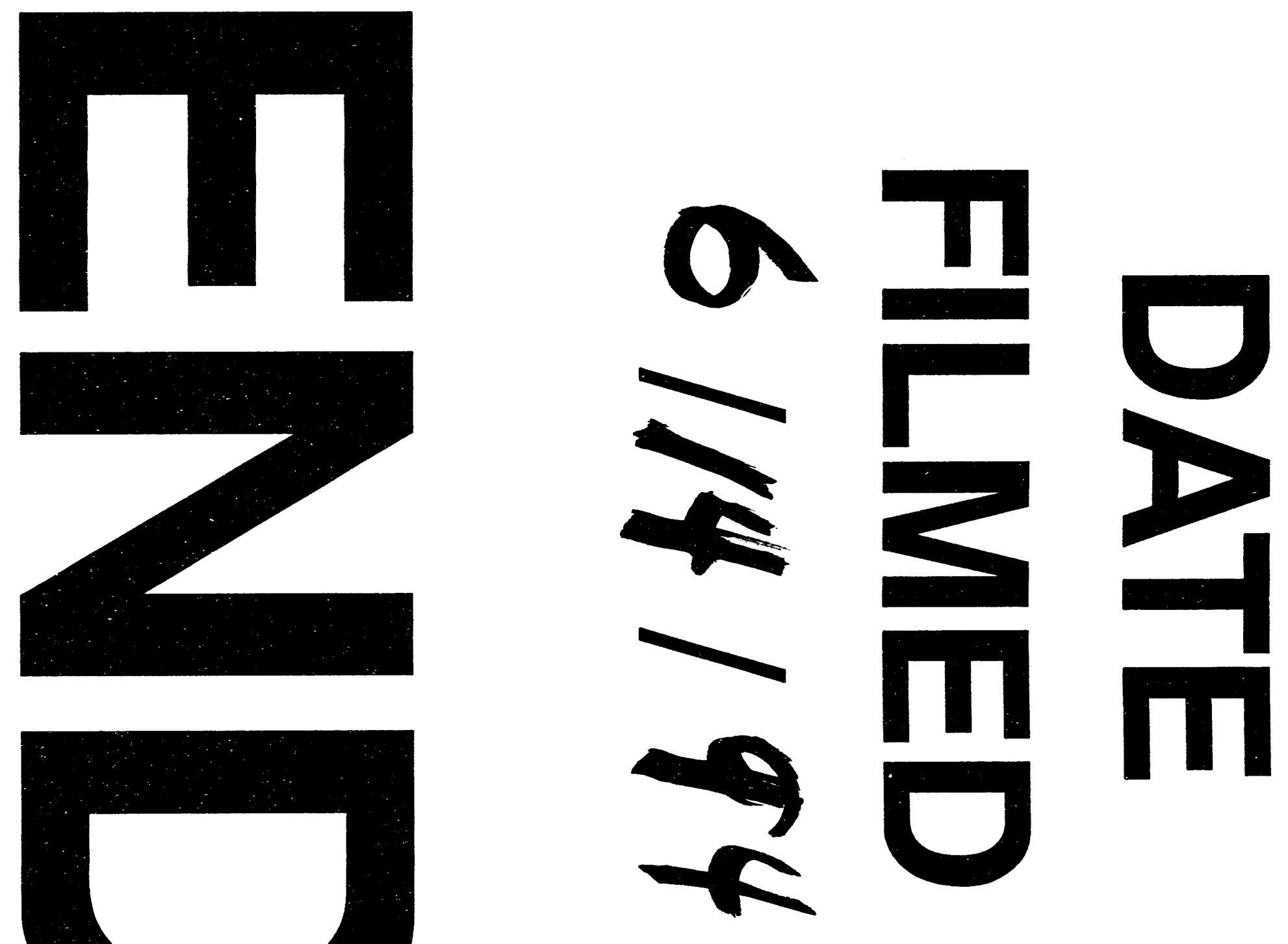
